\title{
Critical Theoretical Frameworks in Engineering Education: An Anti-Deficit and Liberative Approach
}

\author{
Joel Alejandro Mejia ${ }^{1, *(\mathbb{C},}$, Renata A. Revelo ${ }^{2}$, Idalis Villanueva ${ }^{3}$ and Janice Mejia ${ }^{4}(\mathbb{C}$ \\ 1 Department of General Engineering, University of San Diego, 5998 Alcalá Park, San Diego, CA 92110, USA \\ 2 Department of Electrical and Computer Engineering, University of Illinois-Chicago, 1200 W Harrison St, \\ Chicago, IL 60607, USA; revelo@uic.edu \\ 3 Department of Engineering Education, Utah State University, Logan, UT 84322, USA; \\ idalis.villanueva@usu.edu \\ 4 McCormick Office of Undergraduate Engineering, Northwestern University, 633 Clark St, \\ Evanston, IL 60208, USA; j-mejia@northwestern.edu \\ * Correspondence: jmejia@sandiego.edu
}

Received: 10 August 2018; Accepted: 19 September 2018; Published: 22 September 2018

\begin{abstract}
The field of engineering education has adapted different theoretical frameworks from a wide range of disciplines to explore issues of education, diversity, and inclusion among others. The number of theoretical frameworks that explore these issues using a critical perspective has been increasing in the past few years. In this review of the literature, we present an analysis that draws from Freire's principles of critical andragogy and pedagogy. Using a set of inclusion criteria, we selected 33 research articles that used critical theoretical frameworks as part of our systematic review of the literature. We argue that critical theoretical frameworks are necessary to develop anti-deficit approaches to engineering education research. We show how engineering education research could frame questions and guide research designs using critical theoretical frameworks for the purpose of liberation.
\end{abstract}

Keywords: critical theoretical frameworks; anti-deficit approach; engineering education research; critical pedagogy

\section{Introduction}

While critical theoretical frameworks are being used to challenge social practices and belief systems in engineering [1,2], there is a need to dig deeper into the consequences of research whose foci and approach situate underrepresented students as "deficient". Deficit perspectives prevent many underrepresented students and educators from participating in important learning and teaching activities, which further disadvantage students in fields such as engineering [3]. For example, deficit perspectives discourage bilingual children living in high poverty communities from participating in active learning opportunities $[4,5]$.

Ironically, and unfortunately, researchers seeking to understand issues of inclusion, diversity, and retention of underrepresented students could inadvertently ask research questions that focus on the deficits of such populations rather than on their assets [6,7]. Despite deficit perspectives being presented in the literature as lacking empirical validation, research around these beliefs continues to pervade and results in unintended yet dismal consequences on educational practices [6-8].

At the foundation of these deficit perspectives lies the idea that students possess motivational and cognitive deficits. Thus, research that analyzes underrepresented students through deficit-framed questions may perpetuate the idea that these students, particularly students of color and from minoritized groups, have several "needs" [9]. A deficit approach limits the type and forms of 
interventions that could be tailored to the unique contexts and situated in societies that these students are a part of. To counter this deficit narrative in engineering, it is necessary to pose questions and design studies that provide a better understanding of students' constructed world [9], and how "students of color persist and successfully navigate" [10] (p. 67) different engineering pathways.

Traditional scholarships have been normed by epistemological perspectives that have failed to examine structures of domination and oppression in educational settings [11]. As such, there is a need for more diversity in the methods and theoretical frameworks used in engineering education to frame and design research studies that challenge deficit models and center on the assets of underrepresented students rather than their deficits [12]. This study presents ways in which critical theoretical frameworks can be used in fields like engineering education following Freire's principles of critical andragogy and pedagogy [13]. Engineering education was selected for this study due to its recent inception into the research realm [14-18] and due to its normative, hegemonic (primarily composed of white, male, and middle class), and reliance upon meritocratic ideologies [15,16,19-22]. In addition, the study outlines the characteristics of anti-deficit scholarship, and describes the implications of connecting reflection, practice, and research to achieve transformative changes in engineering education.

\section{Positionality}

Educators must reflect into their own biases and limitations and disengage from framing questions that may potentially lead to unintentional promotion of deficit perspectives. Awareness through reflection is the first step to engage in both pedagogical and andragogical research practices that counter such perspectives $[23,24]$. Critical reflection, in particular, is crucial because it can uncover the power dynamics that exist in engineering education, and can help to challenge hegemonic assumptions about students [25]. Thus, researchers must frame questions in terms of power, privilege, and oppression, while engaging in critical reflection [1,26].

The research team encompasses minoritized populations in engineering and engineering education research whose asset-based approaches have helped them excel in engineering. As being placed in positions of power and authority through their existing roles as university faculty at research and teaching institutions, it is the authors' belief that bringing to light this analysis will further encourage future populations of underrepresented and minoritized populations in engineering, via newly informed educational practices, to succeed and persist in the field.

The research team also posits that communities of color and other minoritized groups (e.g., LGBTQ) deserve to be validated and acknowledged by the general and engineering education community. These communities have a wealth of knowledge, skills, and practices that are very rich and powerful [27]. Their meaning-making practices cannot and should not be silenced, sanctioned, nor neglected $[9,27]$. A different worldview of engineering is not a "deficient" interpretation of engineering [27], but a manifestation of the cultural, historical, and social richness of communities of minoritized groups (including but not limited to people of color). Thus, asset-based approaches create the bridges necessary to merge both the formal and informal spaces while acknowledging the lived realities and embodied knowledge of students of color and other minoritized groups in engineering.

\section{Theoretical Framework}

\subsection{Concientização and Praxis}

Freire argued that reflection is necessary because it seeks to overcome the alienating and dehumanizing situation of many individuals $[28,29]$. A lack of reflection prevents individuals from forming the cognitive and motivational tools needed to liberate themselves from the conditioning and historical factors that hinder their development $[13,28,30]$. Transformative changes cannot be achieved unless there is a combination of action built upon reflection, or concientização [1,13], and a theory merged with action, or praxis $[1,13]$. 
Concientização involves three phases of what the individual goes through to achieve liberation: (1) Magical, (2) naïve, and (3) critical. The magical phase is characterized by being in a state of impotence where the individual is unable to do anything about their situation, which was created by the system. As such, the individual is controlled by outside forces (the system or social structure that they are part of) that are simply viewed as causality to the individual's situation [23]. The naïve phase is characterized by a meek understanding of one's situation within the system but with the internalized certainty that one is not capable of changing it. The individual accepts that there are aspects of their life within their reach and others that are not within their reach. The critical phase involves uncovering factors that make individuals different, and due to this distinction, they are able to understand the ways in which the system can be unfair. During the critical phase, individuals realize that the system can be transformed by removing oppressive ideologies and reclaiming power for the benefit of the community [13,28].

For Freire, concientização was always inseparable from liberation. The liberation process is characterized by dialogue [30] and concientização is the ability to hold the most critical possible view of reality $[23,28]$. In the model presented in Figure 1, liberation is reached when there is a combination of theory developed from reflection (e.g., scholarship), action guided by theory (e.g., praxis), and action based on reflection (e.g., concientização). Liberation is also believed to be characterized by radically transforming praxis, and should be understood as a pedagogical method of liberation of oppressed people, although it can be generalized to all types of education and to all types of society, poor or developed [23]. Thus, theory development that is done through reflection leads to scholarship; action that takes into consideration the theory developed can evolve into praxis; and action based on reflection develops into concientização.

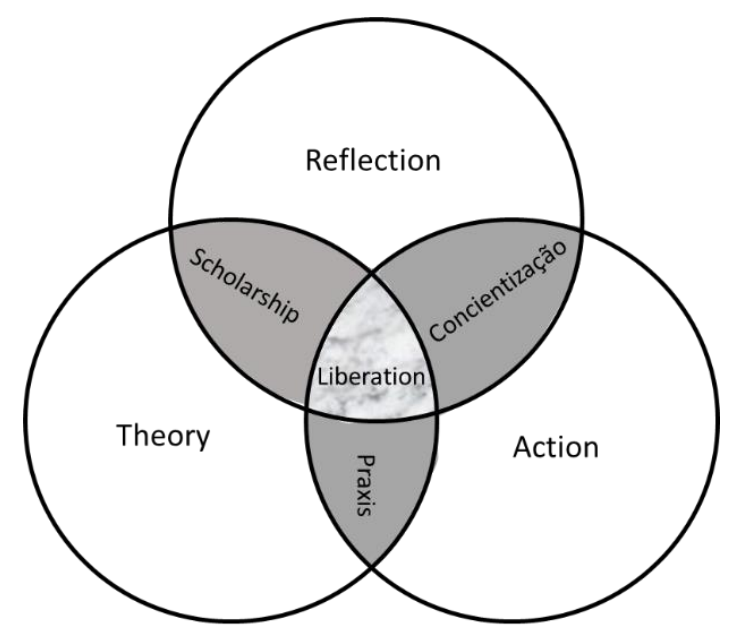

Figure 1. Proposed critical consciousness approach by the authors; model was adapted and expanded upon Freire's principles of critical pedagogy [13].

\subsection{Critical Theoretical Frameworks}

According to Horkheimer [31], there is a distinction between traditional and critical theory. Traditional theory seeks to only understand or describe society, while critical theory seeks to critique and change society. Critical theory recognizes the complexity of social processes and its main task is "to reflect upon the structures from which social realities and the theories that seek to explain it are constructed" [32] (p. 139). Critical theory seeks not only to critique society but also to provide the foundation to transform society as a whole [32]. From its origins in the Frankfurt School and its focus on a criticism of modern social structures [32], critical theory has continued to grow and contribute to the bases for inquiry in other fields such as sociology and education [33-35], pedagogy [13,28,30,36-40], andragogy [41], and other areas including feminism, law, and social sciences [42-51]. 
Critical theories not only describe and critique complex social constructions, they also explore the circumstances that lead to oppression. For instance, Critical Race Theory (CRT) emerged from legal scholarship to provide an overview of the permeation of racism through the legal system [48]. Eventually, scholarship in education integrated CRT to examine and challenge the traditional paradigms that exist in the educational system [37], and analyze how inequalities in schools are the result of a racialized society [39]. CRT has been used as a framework to describe the experiences of students of color in hegemonic spaces, to counter dominant paradigms and narratives, and to better understand the role of agency and empowerment of the oppressed [11,52,53].

Thus, critical theories have been used to provide new perspectives and advocate for an approach that is not primarily positivist or that uses methods to classify the social world in an objective way with causal connection [53-55]. These theories illustrate the ways in which context, gender, culture, society, and other factors can be studied through a critical lens, in order to achieve equity. The impact of critical theories in engineering education could potentially address the problems of underrepresentation in the field by challenging its uninterrogated and institutionalized norms. Nonetheless, using these critical lenses to understand the experiences of underrepresented students in engineering could be detrimental if praxis (the fusion of theory and action) and concientização (action based on reflection) are not achieved [13]. Thus, understanding how to appropriately use critical theoretical frameworks could help scholars and educators analyze the engineering climate, its impact on minoritized populations, guide future research, and provide an opportunity to further improve the ways in which engineering can become more inclusive instead of superficially diverse.

\subsection{Anti-Deficit Framework}

Harper [10] provided a framework that redefines how research questions in science, technology, engineering, and math (STEM) research are framed. He argued that traditional scholarship encompasses a considerable amount of emphasis on "understanding how [underrepresented students] managed to acquire various forms of capital they did not possess upon entry" to different STEM fields [10]. Harper sought to invert the logic of traditional research studies in STEM education by asking questions such as "what do students of color have?", rather than "what do students of color need?". In this way, asset-based approaches promote learning in meaningful and relevant ways while challenging deficit-thinking models.

Aligned with Harper's views, the authors of this paper posit that critical theoretical frameworks, particularly in engineering education research, should explore how reflection, theory and action merge to not only achieve concientização but also praxis. Furthermore, through an anti-deficit approach, educators, students, researchers and their intended participant populations can experience liberation from oppressive forces and their scholarship can serve as a tool to promote this freedom.

As illustrated in Figure 1, the integration of the three concepts of critical pedagogy (theory, reflection, and action) presented by Freire [13] can help conceptualize a new approach to fields like engineering education research. This model was built upon Freire's conceptualization and synthesis of critical pedagogy to show visually how scholarly work can be driven by critical theoretical perspectives. At the intersection of theory and reflection is Scholarship-a state where the scholar has a deep understanding of their reflexivity as a researcher and educator and uses critical theory to inform and conduct research. At the intersection of reflection and action is Concientização-a state where the scholar has a deep understanding of their reflexivity as a researcher and educator, and enacts it not only in research but also in other forms of scholarly work (e.g., advocacy, programs, teaching, service). At the intersection of theory and action is Praxis-a state where the scholar uses critical theory to inform their scholarly work (e.g., research, advocacy, programs, teaching, service). At the intersection of theory, reflection, and action is Liberation-a state where the scholar has reached critical consciousness in all aspects (i.e., theory, reflection, and action) and enacts critical consciousness in all aspects of their work. 
The following study describes how the authors investigated the ways in which engineering education research that has used critical theoretical frameworks in their design has yet to detach itself from research questions framed in a deficit-oriented manner. We focused on studies that utilized critical theoretical frameworks since the foundation of this type of research is to critically analyze how oppressive systems are created and to provide empowerment and liberation for those who are marginalized $[13,28,36,52,53]$.

\section{Methodology}

\subsection{Research Design}

This study is built upon larger and more comprehensive study conducted by the research team $[1,26,56]$. The research team applied qualitative approaches, specifically Critical Discourse Analysis [57], to the analysis of the literature, and applied an interpretive philosophical lens to the findings [58,59]. As indicated by Fairclough [57], Critical Discourse Analysis "takes particular interest in the relation between language and power" (p. 2). Part of using language in particular ways through scholarship is to produce representations and social process and practices that shape specific discourses [57]. Thus, Critical Discourse Analysis was used to assess how engineering education, as an emerging field, has embraced the adoption and application of critical theoretical frameworks. In addition, the intent of the analysis was to identify how the use of critical theoretical frameworks guided the research directed primarily at minoritized populations.

\subsection{Review Questions}

The central review questions that guided this study included:

1. What are the common types of critical theoretical frameworks used to study underrepresented populations in engineering education?

2. How are these critical theoretical frameworks used in within research methodologies for these engineering populations?

\subsection{Systemic Literature Review}

A systematic literature review was conducted as recommended by Khan and colleagues [60] where the authors derived from our formulated review questions, identified relevant studies, selected studies that fit the inclusion criteria, appraised the quality of the research studies, and summarized the evidence by use of an explicit methodology. Based upon our research questions, relevant studies were identified through the following databases: ERIC, IEEE Xplore, Journal of Higher Education, Journal of Engineering Education, ASEE PEER, Journal of Women and Minorities in Science and Engineering, and the Journal of STEM Education. The descriptors "critical theory", "underrepresented minority", "critical race theory", "feminism", "conciencia", and "intersectionality" were used to locate primary sources. These descriptors were also used in conjunction with other descriptors such as "underrepresented populations", “Latino", "Hispanic", "African American”, “Native American”, and "women" as these are all underrepresented populations in engineering [61].

Several articles were identified as potential sources of information, but to assess their quality, only articles that met the following inclusion criteria were reviewed: (1) Published between 2005 and 2016; (2) listed critical theoretical frameworks as one of the lenses for analysis; and (3) investigated K-16 academic engineering education. The papers were divided into the types of critical theoretical frameworks listed in the different manuscripts identified. In total, there were 33 articles reviewed that represented a wide variety of critical theoretical frameworks. Of those 33 articles, only 28 clearly identified the type of critical theoretical framework used. The other five articles simply indicated that the frameworks used or developed were "critical". Each article was reviewed by at least one of the four authors in detail using an agreed-upon coding sheet. 
To summarize the evidence found in these identified articles, a coding sheet was developed based on the characteristics significant to each study evaluated. These categories on the coding sheet included identifying the purpose of the study, the research questions, the methods used, the type of data collected, the population involved in the study, and relevant findings. Additionally, we used our adapted Freirian critical consciousness model (Figure 1) to understand the ways in which the critical theoretical frameworks were used in these publications. After reviewing the articles, we synthesized the preliminary findings and patterns each author saw in their respective notes. The lead author reviewed the notes and preliminary findings to guide the final review.

After the articles were analyzed, the authors developed a representative table of different ways in which the articles framed the research questions. These representative examples were not taken verbatim, but rather synthesized to illustrate how critical research in engineering education can reframe deficit-oriented to anti-deficit questions, as indicated by Harper [10], when guided by critical theory. In addition, we identified Freire's principles of critical pedagogy [13] that were emphasized in the studies to describe how critical theoretical frameworks in engineering education are primarily enacted. In the Results section, we illustrate how we reframed representative research questions posed in the engineering education research studies reviewed and the intersecting principles (theory, reflection, and action) highlighted by the studies analyzed.

\subsection{Limitations}

While this study was conducted on work related to engineering education, it is possible that the authors may have omitted research studies on "STEM" that may have included engineering populations. Furthermore, it is recognized that by selecting publications from 2005 to 2016, we may have omitted earlier studies in engineering. However, the focus of this work was to explore the state-of-the-art of these types of studies in engineering education. Finally, we want to acknowledge that some of the studies reviewed used more than one critical theoretical framework (e.g., Community Cultural Wealth and Funds of Knowledge). However, within our inclusion criteria, we focused on studies that used at least one critical framework and did not analyze the impact of those that may have used a combination of these frameworks.

\section{Results}

The articles identified in the systematic literature review illustrates the growing number of studies that employed a critical theoretical framework by the engineering education research community to explore the histories and experiences of underrepresented populations in engineering. As shown in Table 1, most of the studies incorporated feminist theory (and its variants of feminist thought such as Womanism and Mujerismo) or CRT to analyze the social dynamics in engineering. Other common types of critical theoretical frameworks included intersectionality, community cultural wealth, funds of knowledge, and Bourdieuian frameworks.

The variety of critical theoretical frameworks indicated the openness and effort from the engineering education research community to integrate theoretical lenses to challenge the status quo. However, in terms of praxis, several studies did not combine theory and action while engaging with minoritized groups to ask deeper questions related to power, oppression, and normative practices. Asking critical questions that challenge systems of oppression comprises one of the requirements of critical theoretical frameworks for engineering education. For example, the majority of the papers provided insights and implications for the work but seldom was there evidence of researchers taking actions to fight alongside the participants. Freire argues for the need for revolutionary educators to "fight alongside the people" and not just to 'win the people over' [13] (pp. 94-95).

In answering the review question on how critical frameworks were being used, the authors noted the language used in the research questions and throughout the introductory sections to describe the experiences of these underrepresented groups in engineering. For instance, many of these studies focused on describing a "deficiency" first (e.g., the lack of language proficiency or immediate support 
networks), rather than a characteristic that these populations could "voice" to challenge deficit models, or describing the normative bases and structure for social/educational inequity. The results of some of these studies indicated that students of color "lacked" family support networks or role models, or disregarded the fluidity of identity formation $[1,26]$. In addition, the language used in many of the research questions were also framed with a deficit perspective. Representative paraphrased examples of these research questions are included in Table 2 along with examples of ways in which these research questions could be reframed using an anti-deficit and critical theory-guided approach. While Table 2 provides only representative paraphrased examples of research questions, the authors noted that all of the articles reviewed asked questions that were driven by Scholarship-the intersection of theory and reflection. The lack of Praxis or Concientização in these studies suggests a need to explore these further in engineering education research. Few, if any, papers provided anti-deficit research questions or frameworks.

Table 1. Frequency of critical theoretical frameworks used in engineering education research from 2005 to 2016 addressing underrepresented minorities.

\begin{tabular}{ccc}
\hline Critical Theoretical Framework & Population Addressed & Frequency of Studies \\
\hline Critical Race Theory & Asian Americans, African Americans, Latinxs & 5 \\
\hline $\begin{array}{c}\text { Feminist Theory (including the variants } \\
\text { mujerismo and womanism) }\end{array}$ & Women & 5 \\
\hline Intersectionality Theory & Latinxs, African Americans & 4 \\
\hline Community Cultural Wealth & Latinxs, First-generation students & 3 \\
\hline Funds of Knowledge & $\begin{array}{c}\text { First-generation students } \\
\text { Identity Theory } \\
\text { cultural capital, habitus, socialization) }\end{array}$ & $\begin{array}{c}\text { African Americans, Latinxs, Asian Americans, } \\
\text { White women }\end{array}$ \\
\hline Critical Agency & $\begin{array}{c}\text { Dominant and non-dominant groups } \\
\text { in engineering }\end{array}$ & 2 \\
\hline $\begin{array}{c}\text { Not clearly identified or defined } \\
\text { Durdieuian Frameworks (e.g., social capital, }\end{array}$ & $\begin{array}{c}\text { Dominant and non-dominant groups } \\
\text { in engineering }\end{array}$ \\
\hline
\end{tabular}

Table 2. Representative paraphrased examples of research questions analyzed in the systemic review of critical engineering education research.

\begin{tabular}{lll}
\hline \multicolumn{1}{c}{ Deficit-Oriented Questions } & \multicolumn{1}{c}{ Anti-Deficit Reframing } & Critical Theory Guided Questions \\
\hline $\begin{array}{l}\text { To what extent do Black engineering } \\
\text { students participate in engineering } \\
\text { extracurricular activities? }\end{array}$ & $\begin{array}{l}\text { What stimulates Black engineering } \\
\text { students to participate in engineering } \\
\text { extracurricular activities? }\end{array}$ & $\begin{array}{l}\text { How do engineering extracurricular } \\
\text { activities promote Black engineering } \\
\text { student participation? }\end{array}$ \\
\hline $\begin{array}{l}\text { Why do Latinx students leave the } \\
\text { engineering pipeline? }\end{array}$ & $\begin{array}{l}\text { What compels Latinx students to } \\
\text { persist in engineering despite the } \\
\text { institutional challenges? }\end{array}$ & $\begin{array}{l}\text { What institutional challenges } \\
\text { prevent Latinx students to persist } \\
\text { in engineering? }\end{array}$ \\
\hline $\begin{array}{l}\text { Why are Native American students } \\
\text { unprepared for engineering courses? }\end{array}$ & $\begin{array}{l}\text { How do Native American students } \\
\text { overcome educational disadvantages? }\end{array}$ & $\begin{array}{l}\text { How are institutions responsive to } \\
\text { varied levels of educational preparation } \\
\text { for Native American students? }\end{array}$ \\
\hline $\begin{array}{l}\text { Why do students of color not pursue } \\
\text { graduate degrees in engineering? }\end{array}$ & $\begin{array}{l}\text { What are the typical pathways toward } \\
\text { doctoral degrees for students of color? }\end{array}$ & $\begin{array}{l}\text { What aspects of graduate education in } \\
\text { engineering reinforce inequality for } \\
\text { students of color? }\end{array}$ \\
\hline
\end{tabular}

The systemic review indicated that critical theoretical frameworks are being used in engineering education primarily for the sake of theory development for either research or practice. For example, only one of the articles reviewed used principles of participatory action research methods where participants were partakers of actionable outcomes with the researchers to pursue their study. Based on our model, such an approach for research was the only example we found in our review of Praxis. In general, the studies did not take a critical stance on how engineering knowledge is constructed, who 
participates in engineering, and who decides who becomes an engineer. In terms of critical pedagogy, few studies questioned how to empower students of color (e.g., concientização) or considered taking action and working alongside the students (e.g., praxis) to de-colonize and re-inhabit their spaces, including all of these different domains that students of color inhabit.

The rationale or motivation to study minoritized populations in engineering was also reviewed to determine how critical theoretical frameworks were being adapted and applied when working with these populations. The analysis indicated that most studies focused on a deficiency-driven perspective. This type of research framing provides a narrow view of minoritized populations that can eventually become part of a larger dominant discourse in engineering. For example, there was a predominant notion that students (particularly low-income, underrepresented students) fail in school because such students and their families experience deficiencies that obstruct the learning process (e.g., lack of motivation and inadequate home socialization). Unfortunately, some of these studies did not interrogate power structures and epistemological frameworks that perpetuate this narrative.

One emergent finding to note was that few studies considered how different identities intersect. For example, one of the studies was aimed to study feminist theories and intersectionality in engineering, but upon closer examination, the population did not include literature or rationale for not including international and national non-English language women participants. In several studies, the term Hispanic was mentioned as the population of study, yet there was no distinction between this definition and Latin@/Chican@ nor were there references about the community, demographics, language, culture, etc., that would precisely "de-cluster" these groups [26]. The same applied for engineering education research on Native American and African American populations whose demographics, origins, and sub-cultures were not considered. Neither example provided several implications for the study but failed to suggest strategies to challenge power structures to dismantle oppression of people of color in engineering. The latter finding was seen across all other manuscripts reviewed.

Finally, none of the studies reviewed paid significant attention to the historical contexts of the populations studied. The context provided was limited to the sample of the population studied (e.g., traditional age, women, and residential) or institution studied (e.g., private, predominantly white).

\section{Discussion}

The systematic literature review demonstrated that, although research in engineering education is increasingly adopting critical theoretical frameworks, the intended outcomes of using critical frameworks, such as Concientização and Praxis [31,62], are not being addressed, and as a result, the research does not achieve Liberation. Most of the studies analyzed in this systematic literature review focused on a combination of theory and reflection to produce Scholarship. It is important for engineering education researchers to take into consideration all principles of Freire's critical pedagogy [13] in order to achieve Liberation, which is the state at where a scholar has reached critical consciousness. This action requires integrating all elements of the proposed model (Figure 1).

The findings positioned the authors of this paper to question if selection of critical frameworks for engineering is effectively describing the lived experiences of marginalized groups or achieving the outcomes established by these frameworks. As more and more studies in engineering begin to focus on other dimensions of underrepresentation such as language, immigration, ethnicity, culture, identity, phenotype, sexuality, among others, it will be important for educators/researchers to have a targeted lens when exploring these complex yet important phenomena.

As future uses of critical frameworks in engineering continue, it will be important to consider more purposeful sampling of these underrepresented and minoritized groups. Limiting sampling methods and approaches in critical analysis work could be detrimental to the goal of praxis and concientização, and risk the unintended invalidation or belittling of cultures, languages, and experiences, and never reach the liberation the research intends to achieve. 


\section{Conclusions}

While a robust corpus of literature exists on engineering education research that utilizes critical theoretical frameworks, deficit models still persist in how research is framed, thus normalizing the idea that students of color have several "needs". Re-imagining engineering education from an asset-based approach has a strong propensity to develop a knowledgeable citizenry who understands the importance and value of our human constructed world, while validating and acknowledging the contributions of people of color and minoritized groups to engineering. As a field dominated by hegemonic practices and norms, engineering is a field that greatly needs critical perspectives that could help deconstruct dominant discourses-the combination of language, tools, actions, interactions, technologies, processes, beliefs, and values [63]. The Critical Discourse Analysis approach used in this study highlights the importance of dismantling language and power in traditional scholarship in engineering education. Particularly, it is important to analyze how engineering education may reproduce specific discourses that perpetuate deficit models through deficit-oriented questions and practices. For example, some of the studies included in this review chose to use the word "critical" as a way to describe individual reflexive processes and differences between individuals (primarily people of color and minoritized groups), rather than looking at systems of oppression. There is an underlying assumption that "critical" means being descriptive and reflexive of specific phenomena rather than working through positionality to challenge systemic and institutionalized forms of oppression.

\section{Implications/Recommendations}

After a careful analysis, the authors opted to take action on this paper by developing a series of guiding questions that can help researchers combine all principles of critical pedagogy to achieve liberation for minoritized and underrepresented groups in fields like engineering. As listed in Table 3, sample questions were re-written in a way that considers how praxis and concientização can be accounted for in addition to scholarship for the goal of liberation. It is important to note that throughout the process, some type of member checking needs to take place so that the researchers share their understanding of the results with the participants in an effort to enhance the credibility of findings and trustworthiness [64]. It is important to reflect on each other's understanding of the phenomena being studied, revise the results, take action, and co-create theory together to achieve liberation. These guiding questions are not intended to be prescriptive, but rather to be considered by researchers who are interested in using critical theoretical frameworks for the study of minoritized populations in engineering.

Table 3. Guiding questions for researchers using the adapted model of Freire's principles of critical pedagogy from Figure 1.

\begin{tabular}{llll}
\hline $\begin{array}{l}\text { Freire's Principles of } \\
\text { Critical Pedagogy }\end{array}$ & \multicolumn{1}{c}{ Theory } & \multicolumn{1}{c}{ Action } & Reflection \\
\hline Scholarship & $\begin{array}{l}\text { Is this theory critical and am I } \\
\text { considering the political, } \\
\text { cultural and historical factors } \\
\text { that play a role into } \\
\text { the research? }\end{array}$ & $\begin{array}{l}\text { In what ways is my research and } \\
\text { my relationship with the } \\
\text { participants ensuing that a } \\
\text { liberating action will occur? }\end{array}$ & What is my positionality? \\
\hline Praxis & $\begin{array}{l}\text { Are the theories that I am } \\
\text { trying to explore achieving the } \\
\text { intended goal? }\end{array}$ & $\begin{array}{l}\text { How do I ensure that my research } \\
\text { results can be easily translated } \\
\text { into practice? }\end{array}$ & $\begin{array}{l}\text { How am I reflecting upon my role } \\
\text { as a rearcher in the context of } \\
\text { the phenomenon/population I am } \\
\text { trying to explore? }\end{array}$ \\
\hline Concientização & $\begin{array}{l}\text { Does the theory used assume a } \\
\text { deficit or anti-deficit approach? }\end{array}$ & $\begin{array}{l}\text { What are my assumptions about } \\
\text { the community and the } \\
\text { phenomenon? }\end{array}$ & $\begin{array}{l}\text { In what ways was I mistaken } \\
\text { about the population or the } \\
\text { phenomenon I explored? }\end{array}$ \\
$\begin{array}{l}\text { Liberation (e.g., for } \\
\text { participants) }\end{array}$ & $\begin{array}{l}\text { How can I make sure the theory } \\
\text { development in my work is } \\
\text { liberative and co-created with } \\
\text { participants? }\end{array}$ & $\begin{array}{l}\text { In what ways am I allowing } \\
\text { participants to take action } \\
\text { alongside me in order to achieve } \\
\text { liberation from the obstacles that } \\
\text { prevent action from occurring? }\end{array}$ & $\begin{array}{l}\text { In what ways am I allowing for } \\
\text { participants to reflect with theme } \\
\text { about the research findings and to } \\
\text { co-construct these narratives } \\
\text { together? }\end{array}$ \\
\hline
\end{tabular}


Furthermore, for researchers interested in conducting work in fields like engineering, reflection, theory, and action should not be seen as separate from each other. Another element to consider is that critical researchers do not only describe an event or experiences; they ask questions of power, privilege, and oppression. Engineering is situated against historical underrepresentation of people of color in STEM [65]. If engineering forms from culture and practices, it is a challenge for students of color and other minoritized groups who want to become part of the dominant culture because of what they have to sacrifice, especially when dominant paradigms and deficit models are disseminated through the work of engineering education researchers.

In addition, we cannot separate out the epistemic knowledge from ontological aspects of identities and the realities of minoritized and underrepresented students' everyday lives. For instance, identity work is longitudinal and requires recognition from others. Students start to perform as engineers throughout their educational experiences; however, those experiences are laminated longitudinally. Instead of focusing on the actual student identity or experiences, how can we begin to change the environments? How do we create the spaces in which students are allowed to participate, and redefine and reimagine the notions of what participation means?

Finally, although it was unclear what the researchers' intentions were in pursuing critical research in engineering education, we maintain that there are changes that need to be made for future studies. It is important to engage in critical reflection while the research is being conducted. If the idea is to incorporate critical theoretical frameworks in engineering education research, it is imperative that the researchers include methods that incorporate strategies to "fight alongside" [13] (pp. 94-95) students of color. Borrowing from Freire's work [13], we use the phrase "fight alongside" purposefully to propose a stance where researchers/educators/scholars take a liberated perspective into all of their work. Using such a stance implicates that researchers take an approach that is not just theory-based, but also incorporates reflection and action. We note that from our review, we found most studies were limited to Scholarship (i.e., intersection of theory and reflection) and lacked the action tenet. Additionally, there is no accountability on the methods in which praxis and concientização are achieved. We recommend that research that integrates critical theoretical frameworks include sections on methods, positionality, and reflection that allow the readers to learn more about how to create and sustain transformative approaches.

Author Contributions: Conceptualization, J.A.M., R.A.R. and I.V.; Methodology, J.A.M., R.A.R. and I.V.; Formal Analysis, J.A.M., R.A.R., I.V., and J.M.; Resources, J.A.M., R.A.R., I.V., and J.M.; Conceptualization of Freirian Model, J.A.M., R.A.R. and I.V.; Conceptualization of Tables 2 and 3, J.A.M., R.A.R., I.V., and J.M.; Writing-Original Draft Preparation, J.A.M.; Writing-Review \& Editing, J.A.M., R.A.R., I.V., and J.M.

Funding: This material is based upon work supported by the National Science Foundation (NSF) under Grant No. DRL-1644976 and EEC-1653140. Any opinions, findings, and conclusions or recommendations expressed in this material does not necessarily reflect those of NSF.

Conflicts of Interest: The authors declare no conflict of interest.

\section{References}

1. Mejia, J.A.; Revelo, R.A.; Villanueva, I. The "fibonacci sequence" of critical theoretical frameworks: Breaking the code of engineering education research with underrepresented populations. In Proceedings of the ASEE Annual Conference and Exposition, Columbus, OH, USA, 25-28 June 2017.

2. Pawley, A.; Mejia, J.A.; Revelo, R.A. Translating theory on color-blind racism to an engineering education context: Illustrations from the field of engineering education research with underrepresented populations. In Proceedings of the ASEE Annual Conference and Exposition, Salt Lake City, UT, USA, 24-27 June 2018.

3. Esquinca, A. Socializing pre-service teachers into mathematical discourse: The interplay between biliteracy and multimodality. Multiling. Educ. 2012, 2,1-20. [CrossRef]

4. Adair, J.K.; Colegrove, K.S.-S.; McManus, M.E. How the word gap argument negatively impacts young children of Latinx immigrants' conceptualizations of learning. Harv. Educ. Rev. 2017, 87, 309-334. [CrossRef]

5. Colegrove, K.S.-S.; Adair, J.K. Countering deficit thinking: Agency, capabilities and the early learning experiences of children of Latina/o immigrants. Cont. Issues Early Child. 2014, 15, 122-135. [CrossRef] 
6. Valencia, R.R.; Solórzano, D.G. Contemporary Deficit Thinking; Falmer: New York, NY, USA, 1997; pp. $160-210$.

7. Valenzuela, A. Subtractive Schooling: US-Mexican Youth and the Politics of Caring; State University of New York Press: Albany, NY, USA, 2010.

8. Valencia, R.R. The Mexican American struggle for equal educational opportunity in Mendez v. Westminster: Helping to pave the way for Brown v. Board of Education. Teach. Coll. Rec. 2005, 107, 389-423. [CrossRef]

9. Mejia, J.A.; Wilson-Lopez, A.; Robledo, A.L.; Revelo, R.A. Nepantleros and nepantleras: How Latinx adolescents participate in social change in engineering. In Proceedings of the ASEE Annual Conference and Exposition, Columbus, OH, USA, 25-28 June 2017.

10. Harper, S.R. An anti-deficit achievement framework for research on students of color in STEM. New Dir. Inst. Res. 2010, 148, 63-74. [CrossRef]

11. Delgado Bernal, D. Using a Chicana feminist epistemology in educational research. Harv. Educ. Rev. 1998, 68, 555-583. [CrossRef]

12. Mein, E.; Esquinca, A.; Monarrez, A.; Saldaña, C. Building a pathway to engineering: The influence of family and teachers among Mexican-origin undergraduate engineering students. J. Hispan. High. Educ. 2018, 1, 1-15. [CrossRef]

13. Freire, P. Pedagogy of the Oppressed; Bloomsbury: New York, NY, USA, 2003.

14. Jesiek, B.K.; Newswander, L.K.; Borrego, M. Engineering education research: Discipline, community, or field? J. Eng. Educ. 2009, 98, 39-52. [CrossRef]

15. Davis, M. Engineering as Profession: Some Methodological Problems in Its Study; Springer: New York, NY, USA, 2015; pp. 65-79.

16. Lohmann, J.; Froyd, F. Chronological and ontological development of engineering education as a field of scientific inquiry. Presented at the Second Meeting of the Committee on the Status, Contributions, and Future Directions of Discipline-Based Education Research, Washington, DC, USA, 2010; Available online: https: //sites.nationalacademies.org/cs/groups/dbassesite/documents/webpage/dbasse_072587.pdf (accessed on 22 September 2018).

17. Borrego, M. Development of engineering education as a rigorous discipline: A study of the publication patterns of four coalitions. J. Eng. Educ. 2007, 96, 5-18. [CrossRef]

18. Koro-Ljungberg, M.; Douglas, E.P. State of qualitative research in engineering education: Meta-analysis of jee articles, 2005-2006. J. Eng. Educ. 2008, 97, 163-175. [CrossRef]

19. Downey, G.L.; Lucena, J.C. Knowledge and professional identity in engineering: Code-switching and the metrics of progress. Hist. Technol. 2004, 20, 393-420. [CrossRef]

20. Baillie, C.; Pawley, A.; Riley, D.M. Engineering and Social Justice: In the University and Beyond; Purdue University Press: West Lafayette, IN, USA, 2012.

21. Jolly, L.; Radcliffe, D. Reflexivity and hegemony: Changing engineers. In Proceedings of the 23rd HERDSA Conference, Toowoomba, Australia, 2-5 July 2000; pp. 357-365.

22. Riley, D. Engineering and Social Justice: Synthesis Lectures on Engineers, Technology, and Society; Morgan and Claypool: San Rafael, CA, USA, 2008; pp. 1-152.

23. Lawrence, L.C. La concientización de paulo freire. Historia de la Educación Colombiana 2008, 11, 51-72.

24. Melnyk, R.; Novoselich, B.J. The role of andragogy in mechanical engineering education. In Proceedings of the ASEE Annual Conference and Exposition, Columbus, OH, USA, 25-28 June 2017.

25. Brookfield, S. The concept of critical reflection: Promises and contradictions. Eur. J. Soc. Work 2009, 12, 293-304. [CrossRef]

26. Revelo, R.A.; Mejia, J.A.; Villanueva, I. Who are we? Beyond monolithic perspectives of Latinxs in engineering. In Proceedings of the ASEE Annual Conference and Exposition, Columbus, OH, USA, 25-28 June 2017.

27. Mejia, J.A.; Pulido, A. Fregados pero no jodidos: A case study of Latinx rasquachismo. In Proceedings of the ASEE Annual Conference and Exposition, Salt Lake City, UT, USA, 24-27 June 2018.

28. Freire, P. The Politics of Education: Culture, Power, and Liberation; Bergin and Garvey: South Hadley, MA, USA, 1985.

29. Giroux, H.A. Rethinking education as the practice of freedom: Paulo Freire and the promise of critical pedagogy. Policy Futures Educ. 2010, 8, 715-721. [CrossRef]

30. Freire, P. Reading the world and reading the word: An interview with Paulo Freire. Lang. Arts 1985, 62, 15-21. 
31. Horkheimer, M. Traditional and Critical Theory: Selected Essays; Herder and Herder: New York, NY, USA, 1976; pp. 188-243.

32. González, F.; Moskowitz, A.; Castro-Gómez, S. Traditional vs. Critical cultural theory. Cult. Crit. 2001, 49, 139-154.

33. Bourdieu, P. The forms of capital. Cult. Theory Anthol. 2011, 1, 81-93.

34. Bourdieu, P.; Passeron, J.-C. Reproduction in Education, Society and Culture; Sage: Beverly Hills, CA, USA, 1990.

35. Bourdieu, P.; Wacquant, L.J. An Invitation to Reflexive Sociology; University of Chicago Press: Chicago, IL, USA, 1992.

36. Shor, I.; Freire, P. A Pedagogy for Liberation: Dialogues on Transforming Education; Bergin and Garvey: South Hadley, MA, USA, 1987.

37. Ladson-Billings, G. Toward a theory of culturally relevant pedagogy. Am. Educ. Res. J. 1995, 32, 465-491. [CrossRef]

38. Ladson-Billings, G. Just what is critical race theory and what's it doing in a nice field like education. Qual. Stud. Educ. 1996, 11, 7-24. [CrossRef]

39. Ladson-Billings, G.; Tate, W.F. Toward a critical race theory of education. Teach. Coll. Rec. 1995, 97, 47-68.

40. Ladson-Billings, G.; Tate, W.F. Education Research in the Public Interest: Social Justice, Action, and Policy; Teachers College Press: New York, NY, USA, 2006.

41. Wilson, A.L.; Kiely, R.C. Towards a critical theory of adult learning/education: Transformational theory and beyond. In Proceedings of the Adult Education Research Conference, Raleigh, NC, USA, 24-26 May 2002.

42. Foucault, M. The history of sexuality: An introduction, volume i. In Trans. Robert Hurley; Vintage: New York, NY, USA, 1990.

43. Crenshaw, K. Critical Race Theory: The Key Writings that Formed the Movement; The New Press: New York, NY, USA, 1995.

44. Crenshaw, K. Demarginalizing the intersection of race and sex: A black feminist critique of antidiscrimination doctrine, feminist theory and antiracist politics. U. Chi. Legal F. 1989, 1, 139-167.

45. Crenshaw, K.W. Toward a race-conscious pedagogy in legal education. Nat'l Black LJ 1988, 11, 1-14.

46. Delgado, R. When a story is just a story: Does voice really matter? Va. Law Rev. 1990, 76, 95-111. [CrossRef]

47. Delgado, R.; Stefancic, J. Critical race theory: An annotated bibliography. Va. Law Rev. 1993, 79, 461-516. [CrossRef]

48. Delgado, R.; Stefancic, J. Critical Race Theory: An Introduction; NYU Press: New York, NY, USA, 2017.

49. Delgado-Bernal, D. Critical race theory, latino critical theory, and critical raced-gendered epistemologies: Recognizing students of color as holders and creators of knowledge. Qual. Inq. 2002, 8, 105-126. [CrossRef]

50. Delgado-Bernal, D.; Villalpando, O. An apartheid of knowledge in academia: The struggle over the "legitimate" knowledge of faculty of color. Equity Excell. Educ. 2002, 35, 169-180. [CrossRef]

51. Bell, D.A. Serving two masters: Integration ideals and client interests in school desegregation litigation. Yale Law J. 1976, 85, 470-516. [CrossRef]

52. Solorzano, D.G.; Yosso, T.J. Critical race and latcrit theory and method: Counter-storytelling. Int. J. Qual. Stud. Educ. 2001, 14, 471-495. [CrossRef]

53. Solórzano, D.G.; Yosso, T.J. Critical race methodology: Counter-storytelling as an analytical framework for education research. Qual. Inq. 2002, 8, 23-44. [CrossRef]

54. Giroux, H. Pedagogy and the Politics of Hope: Theory, Culture, and Schooling: A Critical Reader; Routledge: Abingdon-on-Thames, UK, 2018.

55. Giroux, H. Theories of reproduction and resistance in the new sociology of education: A critical analysis. Harv. Educ. Rev. 1983, 53, 257-293. [CrossRef]

56. Villanueva, I.; Gelles, L.; Di Stefano, M.; Smith, B.; Tull, R.; Lord, S.; Benson, L.; Hunt, A.; Riley, D. What does hidden curriculum in engineering look like ad how can it be explored? In Proceedings of the American Society of Engineering Education Annual Conference and Exposition, Salt Lake City, UT, USA, 24-27 June 2018.

57. Fairclough, N. Critical Discourse Analysis: The Critical Study of Language; Routledge: New York, NY, USA, 2013.

58. Creswell, J.W.; Creswell, J.D. Research Design: Qualitative, Quantitative, and Mixed Methods Approaches; Sage Publications: Thousand Oaks, CA, USA, 2017.

59. Denzin, N.K.; Lincoln, Y.S. The Sage Handbook of Qualitative Research; Sage: Beverly Hills, CA, USA, 2011.

60. Khan, K.S.; Kunz, R.; Kleijnen, J.; Antes, G. Five steps to conducting a systematic review. J. R. Soc. Med. 2003, 96, 118-121. [CrossRef] [PubMed] 
61. President's Council of Advisors on Science and Technology. Engage to Excel: Producing One Million Additional College Graduates with Degrees in Science, Technology, Engineering, and Mathematics; President's Council of Advisors on Science and Technology: Washington, DC, USA, 2012.

62. Horkheimer, M. Critical Theory; Continuum: New York, NY, USA, 1982.

63. Gee, J.P. Social Linguistics and Literacies: Ideology in Discourses, 5th ed.; Routledge: New York, NY, USA, 2015.

64. Thomas, D.R. A general inductive approach for analyzing qualitative evaluation data. Am. J. Eval. 2006, 27, 237-246. [CrossRef]

65. Landivar, L.C. Disparities in Stem Employment by Sex, Race, and Hispanic Origin; U.S. Census Bureau: Washington, DC, USA, 2013; pp. 1-25.

2018 by the authors. Licensee MDPI, Basel, Switzerland. This article is an open access article distributed under the terms and conditions of the Creative Commons Attribution (CC BY) license (http://creativecommons.org/licenses/by/4.0/). 